\title{
The Staphylococcus aureus Map protein is an immunomodulator that interferes with $T$ cell-mediated responses
}

\author{
Lawrence Y. Lee, ${ }^{1}$ Yuko J. Miyamoto, ${ }^{2}$ Bradley W. McIntyre, ${ }^{2}$ Magnus Höök, ${ }^{1}$ \\ Kirk W. McCrea, ${ }^{1}$ Damien McDevitt, ${ }^{1}$ and Eric L. Brown ${ }^{1}$ \\ ${ }^{1}$ The Center for Extracellular Matrix Biology, Texas A\&M University System Health Science Center,
Albert B. Alkek Institute of Biosciences and Technology, Houston, Texas, USA
${ }^{2}$ Department of Immunology, The University of Texas M.D. Anderson Cancer Center, Houston, Texas, USA
}

Staphylococcus aureus (SA) is an opportunistic pathogen that affects a variety of organ systems and is responsible for many diseases worldwide. SA express an MHC class II analog protein (Map), which may potentiate SA survival by modulating host immunity. We tested this hypothesis in mice by generating Map-deficient SA (Map-SA) and comparing disease outcome to wild-type Map ${ }^{+}$SA-infected mice. Map-SA-infected mice presented with significantly reduced levels of arthritis, osteomyelitis, and abscess formation compared with control animals. Furthermore, Map-SA-infected nude mice developed arthritis and osteomyelitis to a severity similar to $\mathrm{Map}^{+} \mathrm{SA}$-infected controls, suggesting that $\mathrm{T}$ cells can affect disease outcome following SA infection and Map may attenuate cellular immunity against SA. The capacity of Map to alter $\mathrm{T}$ cell function was tested more specifically in vitro and in vivo using native and recombinant forms of Map. T cells or mice treated with recombinant Map had reduced $\mathrm{T}$ cell proliferative responses and a significantly reduced delayed-type hypersensitivity response to challenge antigen, respectively. These data suggest a role for Map as an immunomodulatory protein that may play a role in persistent $\mathrm{SA}$ infections by affecting protective cellular immunity.

J. Clin. Invest. 110:1461-1471 (2002). doi:10.1172/JCI200216318.

\section{Introduction}

Staphylococcus aureus (SA) is an opportunistic pathogen that colonizes the skin (primarily the anterior nasal vestibule) of approximately $20 \%$ of the population without causing clinical symptoms $(1,2)$. If, however, the skin is damaged by trauma, inoculation by needles, or direct implantation of medical devices, SA can gain entry into

Received for publication July 1, 2002, and accepted in revised form September 23, 2002.

Address correspondence to: Eric L. Brown, The Center for Extracellular Matrix Biology, Texas A\&M University Health Science Center, Albert B. Alkek Institute of Biosciences and Technology, 2121 West Holcombe Boulevard, Suite 603, Houston, Texas 77030-7552, USA. Phone: (713) 677-7572; Fax: (713) 677-7576; E-mail: ebrown@ibt.tamu.edu.

Yuko J. Miyamoto's present address is: Department of Pharmacology, School of Medicine, University of North Carolina, Chapel Hill, North Carolina, USA.

Kirk W. McCrea's present address is: University of Michigan, School of Public Health, Ann Arbor, Michigan, USA.

Damien McDevitt's present address is: Microbiology

Department, Glaxo-Smith-Kline Pharmaceuticals,

Collegeville, Pennsylvania, USA.

Conflict of interest: The authors have declared that no conflict of interest exists.

Nonstandard abbreviations used: Staphylococcus aureus (SA); microbial surface components recognizing adhesive matrix molecules (MSCRAMMs); delayed-type hypersensitivity (DTH); temperature sensitive origin of replication (ts ori); decorinbinding protein $\mathrm{A}(\mathrm{DbpA})$; Lennox broth (LB); binding buffer (BB); inactive B. burgdorferi (iBb); antigen-presenting cells (APCs); 3-\{4,5-Dimethylthizol-2-y\}-2,5diphenyl-tetraxolium bromide (MTT); propidium iodide (PI); microbial immunomodulatory molecule (MIM); open-reading frames (ORF). the host and colonize and infect a variety of tissues (3). SA can cause lethal infections often associated with abscess formation such as endocarditis and pneumonia. Due to a developing resistance to multiple antibiotics, $\mathrm{SA}$ is recognized worldwide as a major health threat $(2,4-7)$.

Adherence of SA to host tissues is mediated by a family of adhesins termed MSCRAMMs (microbial surface components recognizing adhesive matrix molecules), and expression of MSCRAMMs appears to be necessary for colonization of different tissues (8). The SA Map (MHC class II analog protein) protein, also referred to as EAP and $\mathrm{p} 70$, is a secreted protein that can bind to a variety of ECM components, including fibronectin, fibrinogen, vitronectin, bone sialoprotein, and thrombospondin (9-18). Map-deficient SA, however, is not impaired in its adhesion to different ECM components, suggesting that other adhesins can mediate SA adherence to the ECM and that Map may serve functions other than that of an adhesin $(19,20)$. Map contains six repeated domains of 110 amino acids; each containing a 30 -amino acid subdomain with similarity to a sequence in the peptide-binding groove of the MHC class II $\beta$ chain of various mammals (21). This striking similarity between Map and MHC II molecules suggested the possibility that Map may posses the ability to affect $\mathrm{T}$ cell function.

Map has been demonstrated to induce immunoglobulin synthesis and the proliferation of blood mononuclear cells in addition to shifting $\mathrm{T}$ cell responses in a Th2 direction $(12,13,20,21)$. The effects of Map on $\mathrm{T}$ cell responses may play a critical role in SA survival since 
the induction of Th1 (cellular immunity) responses during the course of SA infections have been associated with bacterial clearance in mice (22). The role of T cells in protection against SA infections in humans is less welldefined. SA infections do not usually result in protective immunity, and individuals can be subjected to persistent and repeated staphylococcal infections (23-26). While SA infections affecting the skin appear to be exacerbated by strong Th1-type response, it is clear that cellular immunity is critical in orchestrating the clearance of systemic SA infections and in preventing reinfection with the same or similar pathogen(s) (27-31). The capacity of Map to inhibit or shift the T cell response in a Th2 direction may serve as an additional mechanism facilitating SA survival and persistence.

Recently, Map has been described as an anti-inflammatory agent with the capacity to interfere with the innate host defense systems by preventing neutrophil recruitment, primarily by interacting with ICAM- 1 on endothelial cells (20). In the studies reported here, we demonstrate that Map can also interfere with acquired immunity in a chronic murine SA-infection model (32). We demonstrated that $\mathrm{BALB} / \mathrm{c}$ mice infected with SA genetically manipulated to be deficient in Map (Map-SA) had significantly reduced levels of arthritis and abscess formation (heart and kidneys) following reinfection with wild-type SA (Map $\left.{ }^{+} \mathrm{SA}\right)$ compared with mice infected and reinfected with $\mathrm{Map}^{+} \mathrm{SA}$ or mice receiving a single inoculum of Map ${ }^{+}$SA. Furthermore, when T cell-deficient nude mice $(n u / n u)$ were used in SA infection studies, Map-SA was only marginally less effective in causing arthritis and osteomyelitis compared with $\mathrm{Map}^{+} \mathrm{SA}_{-}$ infected nude mice. Conversely, infections of the genotype control mice $(n u /+)$ with $\mathrm{Map}^{+} \mathrm{SA}$ or Map-SA, respectively, resulted in disease presentation similar to that observed in SA-infected BALB/c mice. Since Th1 responses appear to be important in the control of SA infections (22), we examined the ability of isolated native or recombinant Map to modulate the Th1-mediated delayed-type hypersensitivity (DTH) response in mice and the effects of recombinant Map on the proliferation of a Th1 cell line in vitro. These data suggest that Map is a virulence factor that may play a role in SA persistence and survival by altering $\mathrm{T}$ cell function in vivo; however, it is unclear if and how Map's homology to MHC II relates to its $\mathrm{T}$ cell inhibitory properties.

\section{Methods}

Mice. Specific pathogen-free $\left(\mathrm{MTV}^{-}\right) \mathrm{BALB} / \mathrm{c}$, $\mathrm{C} 3 \mathrm{H} / \mathrm{Hen}, n u / n u$ (nude), and $n u /+$ mice were purchased from Harlan Sprague Dawley (Indianapolis, Indiana, USA). The animals were maintained in facilities approved by the American Association for Accreditation of Laboratory Animal Care in accordance with current regulations and standards of the United States Department of Agriculture, Department of Health and Human Services, and NIH. All animal procedures were approved by the Institutional Animal Care and Use Committee. In the experiments reported here we used female mice that were 8-10 weeks old at the start of each experiment.

Construction of a SA strain Newman Map deletion mutant. An allelic-replacement mutagenesis strategy was adopted to replace the native map locus with a gene that encodes drug resistance in SA strain Newman. The map gene and its up- and downstream flanking sequences were cloned on two overlapping plasmids: pMap5 harboring $1.9 \mathrm{~kb}$ of the map gene and $3.3 \mathrm{~kb}$ of downstream sequence and pMap6 harboring $1 \mathrm{~kb}$ of the map gene and $1 \mathrm{~kb}$ of upstream sequence. These are pBluescript $\mathrm{SK}(+)$ plasmids containing gene fragments from the original lambda gt 11 library of SA strain FDA 574 (21). The 3.3-kb downstream sequence of map was PCR amplified using pMap5 as template and primers R1 (NcoI/HincII), 5'-TGACCATGGCGTCGACATTTGTAGAGATGT-3' (2174-2202 bp) and F1 (T7 primer from pBluescript), 5'-AATACGACTCACTATAGG-3'. The PCR product was purified, digested with $K p n I / N c o I$ and the 1.7-kb digestion product was gel purified and ligated into pMap6, which had been digested with KpnI/NcoI to remove the map sequence. The resulting plasmid pMap7 contained both flanking sequences and only 50 nucleotides of the map gene.

Plasmid pRN6680 was digested with HincII/SmaI and the $t m n-\mathrm{Tc}^{\mathrm{R}}$ marker was blunt-end ligated into HincIIdigested pMap7 to generate plasmid pMap8 (33). To construct a shuttle plasmid that would replicate in SA but had a temperature sensitive origin of replication ( $t s$ ori), plasmid pMap8 was ligated with the SA ts ori from pE194. This ts ori is on a 3.7-kb PstI fragment that had been cloned from PRN5101 into the PstI site in pBluescript. The PstI sites of this ts ori were filled in and ligated into the SmaI site of pMap8. The resulting plasmid was called pMap9. Plasmid pMap9 was introduced into SA strain RN4220 by electroporation and then plated on TSA containing $10 \mu \mathrm{g} / \mathrm{ml}$ tetracycline and incubated at $30^{\circ} \mathrm{C}(34,35)$. The temperature sensitivity of plasmid pMap9 in RN4220 was confirmed. The growth of a culture at $40^{\circ} \mathrm{C}$ in the presence of $10 \mu \mathrm{g} / \mathrm{ml}$ of tetracycline selected for plasmid pMap9 loss and isolation of mutants where allelic-replacement had occurred. The Dmap:tmn mutation was then transferred from SA strain RN4220 into SA strain Newman by phage 85 transduction (36). The correct chromosomal mutations in both strains RN4220 and Newman were confirmed by Southern hybridization analysis using gene probes for both the map and tmn genes (data not shown). Western immunoblotting of proteins released from the cell surface of Newman wild-type and Newman Dmap:tmn cells with $1 \mathrm{M} \mathrm{LiCl}$ also confirmed that the mutant failed to express the Map protein (data not shown).

Expression and purification of recombinant proteins. A recombinant version of Map designated Map19, decorin-binding protein A (DbpA), Ace19 and Ace40, were expressed using the $\mathrm{PQE}$ vector (QIAGEN Inc., Chatsworth, California, USA) in Escherichia coli (JM101) (Stratagene, La Jolla, California, USA) harboring the corresponding plasmids (Table 1) (37-41). The 
Table 1

Recombinant proteins

\begin{tabular}{lll}
\hline Protein & Relevant characteristics \\
Map19 & $30 \mathrm{kDa}$; recombinant His tag protein contains the first and second MHC II analog domains \\
& from S. aureus strain FDA574, potential MSCRAMM, and anti-inflammatory agent \\
Ace40 & $40 \mathrm{kDA}$; recombinant His tag protein contains the minimal collagen-binding domain from E. faecalis, MSCRAMM \\
Ace19 & $19 \mathrm{kDa}$; recombinant His tag protein (40), Truncated form of Ace40 with no collagen-binding activity, MSCRAMM \\
DbpA & $20 \mathrm{kDa}$; recombinant His tag protein, Decorin-binding protein A from B. burdorferi, MSCRAMM
\end{tabular}

resulting proteins contain an $\mathrm{N}$-terminal His tag that allowed for purification using metal ion-chelating chromatography. Map19 contains residues 50-237 encompassing the first and second MHC II analog subdomains and is derived from strain FDA574 (21). The amino acid sequence is $84 \%$ identical and $95 \%$ similar to that of Newman Map in this region (21). E. coli were grown at $37^{\circ} \mathrm{C}$ in Lennox broth (LB) containing the appropriate antibiotics until they reached an $\mathrm{A}_{600}$ of 0.6 (42). Isopropyl- $\beta$-D-thiogalactopyranoside (Life Technologies Inc., Gaithersburg, Maryland, USA) was added to a final concentration of $0.2 \mathrm{mM}$, and the cells were incubated at $37^{\circ} \mathrm{C}$ for an additional 4 hours. Cells from a 1-1 culture were harvested by centrifugation, resuspended in $10 \mathrm{ml}$ binding buffer (BB) $(20 \mathrm{mM}$ Tris $\mathrm{HCl}$, $0.5 \mathrm{M} \mathrm{NaCl}, 15 \mathrm{mM}$ imidazole, $\mathrm{pH}$ 8.0), and lysed in a French pressure cell at 11,000 pounds/inch ${ }^{2}(41)$. The lysate was centrifuged at $40,000 \mathrm{~g}$ for 15 minutes and the supernatant filtered through a $0.45-\mu \mathrm{m}$ filter. A 1-ml iminodiacetic acid Sepharose column (SigmaAldrich, St. Louis, Missouri, USA) was charged with 75 $\mathrm{mM} \mathrm{NiCl} 2 \cdot 6 \mathrm{H}_{2} \mathrm{O}$ and equilibrated with $\mathrm{BB}$. The filtered supernatant was applied to the column and washed with 10 volumes of $\mathrm{BB}$, then 10 volumes of $\mathrm{BB}$ containing $60 \mathrm{mM}$ imidazole. The bound proteins were eluted with BB containing $200 \mathrm{mM}$ imidazole, dialyzed against PBS containing $10 \mathrm{mM}$ EDTA, then dialyzed against PBS (41). Protein concentrations were determined by the bicinchoninic acid protein assay (Pierce Chemical Co., Rockford, Illinois, USA), and proteins were stored at $-20^{\circ} \mathrm{C}$ until use.

Quantitation of SA and intravenous injections. $\mathrm{Map}^{+} \mathrm{SA}$ and Map-SA (strain Newman) were grown overnight in LB (Difco Laboratories, Detroit, Michigan, USA) media at $37^{\circ} \mathrm{C}$ with shaking and were used in all infection experiments. Five hundred microliters of this culture was used to inoculate $50 \mathrm{ml}$ of fresh LB in a 250-ml Erlenmeyer flask. The new cultures were grown as above until the optical density reached 0.5 at $600 \mathrm{~nm}$ using a $1-\mathrm{cm}$ quartz cuvette. Aliquots of each culture were quantified for colony-forming units. The remainder of each culture was washed three times in sterile PBS. The cultures, based on prior growth curve determinations, were diluted to approximately $2 \times 10^{7} \mathrm{CFU} / \mathrm{ml}$. Mice were injected intravenously with $10^{7} \mathrm{SA}$ in $0.5 \mathrm{ml} \mathrm{PBS}$ and monitored for up to 8 weeks. At the conclusion of the experiment, mice were sacrificed and the joints were examined histologically for osteomyelitis and arthritis as described previously $(43,44)$. Briefly, histopathological examination of hematoxylin- and eosin-stained formalin-fixed hind tibiotarsal joints were scored according to the level of cellular infiltrate (primarily neutrophils) as follows: 0 , no arthritis/osteomyelitis; 1 , minimal or rare $(<10 \%$ tissue involvement); 2 , mild (10-20\%); 3 , frequent (20-50\%); 4 , severe $(>50 \%)(43,44)$. All sections were examined without knowledge of the infection status of the mouse.

Quantification of SA in tissues. Mice (four mice/group) were infected with Map-SA or Map $\mathrm{MA}^{+}$as described above. Mice were sacrificed at various time points after infection (0.5, 1, 2, and 4 days), and their blood, heart, kidneys, and tibiotarsal joints (devoid of skin) were collected. Blood was collected aseptically into sterile Vacutainer tubes containing sodium heparin (Becton Dickinson and Co., Franklin Lakes, New Jersey, USA) as described $(43,44)$. The heart and both kidneys were collected aseptically and homogenized under sterile conditions using a mortar and pestle. Both hind tibiotarsal joints were homogenized using a Brinkman PT 10/35 homogenizer under sterile conditions. All homogenized tissues were serially diluted in sterile PBS and inoculated onto 5\% sheep blood agar plates to estimate the bacterial density for each tissue. Plates were incubated at $37^{\circ} \mathrm{C}$, and the number of colonies were counted $24-48$ hours later. No

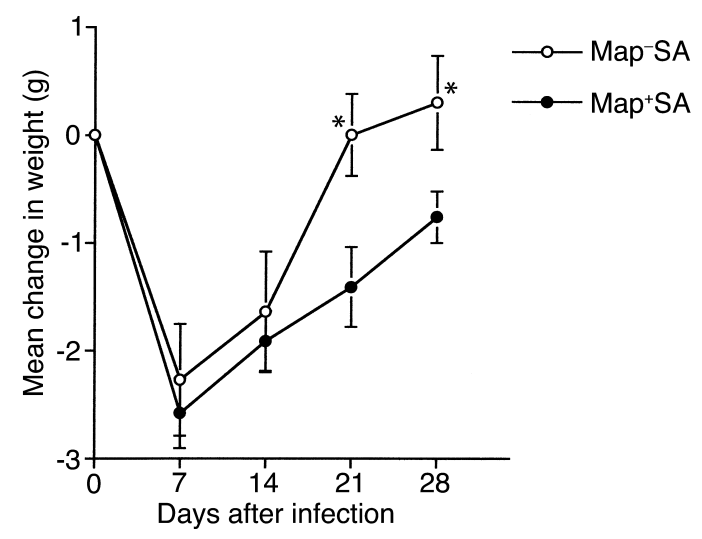

Figure 1

Mean weight loss from Map-SA- and Map ${ }^{+}$SA-infected mice. Mice were intravenously infected with either $10^{7} \mathrm{Map}^{-\mathrm{SA}}$ or Map ${ }^{+} \mathrm{SA}$. Weights were taken before infection and every 7 days after infection for 4 weeks. Data are expressed as the mean \pm SE of the mean of 26 and 24 mice/group for Map-SA- and Map ${ }^{+}$SA-infected mice, respectively. ${ }^{*} P<0.05$, Student $t$ test. 

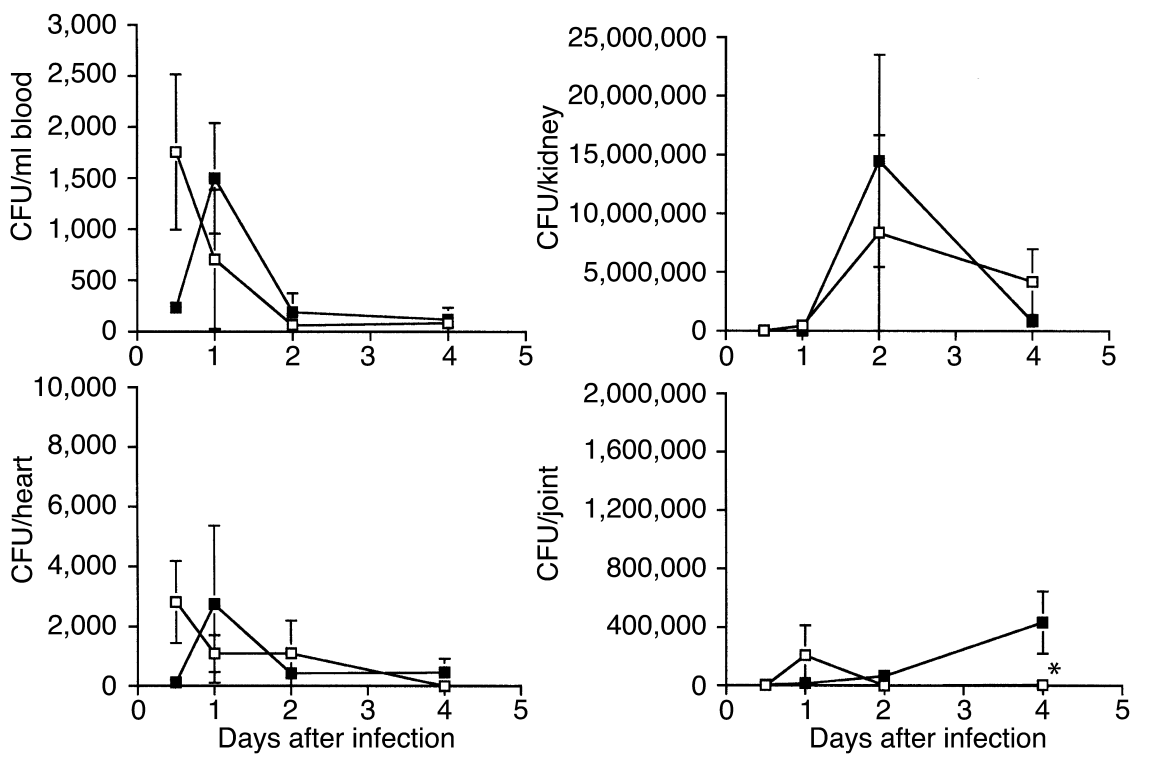

\section{Figure 2}

The number of bacteria isolated from various tissues. CFUs from blood, heart, kidneys, and joints were determined from mice infected with either Map-SA (open squares) or Map ${ }^{+}$SA (filled squares) at various times after infection. Data are expressed as the mean CFU \pm SE of the mean of 4 mice/group at each time point. There was no statistical differences between infection groups at any of the time points examined (Student $t$ test). *The bacterial density in the joints harvested from Map-SA-infected mice 4 days after infection was $5,750 \pm 2,453$. bacterial colonies were detected in tissues harvested and cultured from uninfected mice.

Extraction of Map from SA. Map ${ }^{+} S A$ and Map-SA were grown overnight as described above. Bacteria were pelleted by centrifugation and resuspended in $1 \mathrm{M} \mathrm{LiCl}$ (onetenth of the original media volume). The suspension was incubated at $42^{\circ} \mathrm{C}$ with shaking for 2 hours. The bacteria were pelleted and the supernatant containing noncovalently attached surface proteins was removed and quantified for protein by determining the $\mathrm{A}_{280}$ using $1 \mathrm{M}$ $\mathrm{LiCl}$ as a blank. Extracted proteins were diluted to 0.2 $\mathrm{mg} / \mathrm{ml}$ in PBS and passed through a $0.22-\mu \mathrm{m}$ filter for sterilization prior to intraperitoneal injection (45).

DTH assay. Mice were immunized with $20 \mu \mathrm{g}$ of DbpA in CFA (Sigma-Aldrich) (day 0) (44). Seven days after immunization, mice were challenged in the hind footpads with $2.5 \mu \mathrm{g} \mathrm{DbpA}(50 \mu \mathrm{l}$ PBS) (44). At the time of immunization, days 2,4 , and 6 after immunization, mice were injected intraperitoneally with $100 \mu \mathrm{g}$ of native Map extracted from $\mathrm{Map}^{+} \mathrm{SA}$, supernatant from Map-SA, or with various concentrations $(1-500 \mu \mathrm{g})$ of the recombinant proteins Map19, Ace19, or Ace40 in $500 \mu \mathrm{l}$ of PBS $(38,39,41,46-48)$. The footpads were measured before challenge and 24 hours later, using a spring-loaded micrometer (Mitutoyo, Tokyo, Japan). Mice were anesthetized with Isoflurane during footpad measurements (49).

Adoptive T cell transfer. BALB/c mice (five mice/group) were immunized with DbpA and were treated with

\section{Figure 3}

Hematoxylin- and eosin-stained tissue sections from Map-SA- or Map ${ }^{+} S A$-infected mice. (a) Severe osteomyelitis (BALB/c mouse infected with Map ${ }^{+} S A$ ). (b) No arthritis or osteomyelitis (BALB/c mouse infected with Map-SA). (c-d) Severe arthritis (nu/nu and $n u /+$ mice infected with either Map-SA or Map ${ }^{+} \mathrm{SA}$, respectively). (e-f) Kidney sections (BALB/c mice infected with Map-SA or Map ${ }^{+} S A$, respectively) and ( $\mathbf{g}-\mathbf{h})$ heart sections (BALB/c mice infected with Map-SA or Map ${ }^{+} \mathrm{SA}$, respectively). recombinant Map19 or recombinant Ace40 as described above. The day after the last Map 19 or Ace 40 treatment, mice were sacrificed, and the spleens from each treatment group were enriched for $T$ cells by passage over nylon wool columns as described previously (50). Twenty-four hours after intraperitoneal injection a

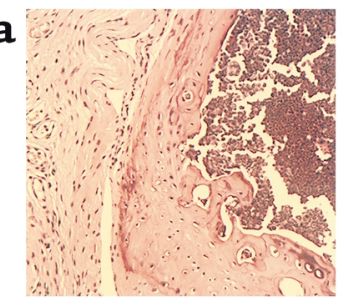

c

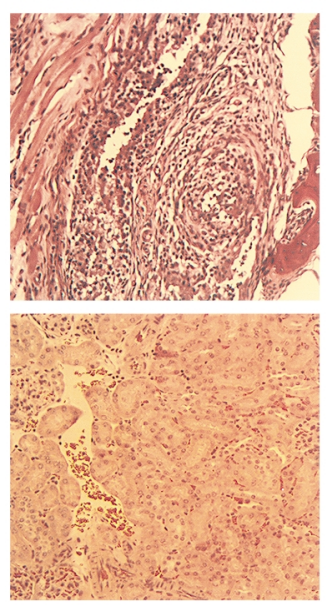

g

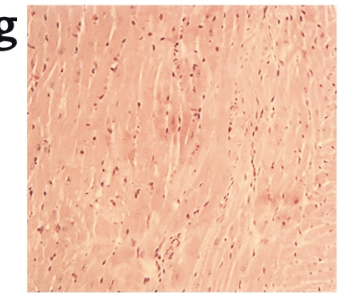

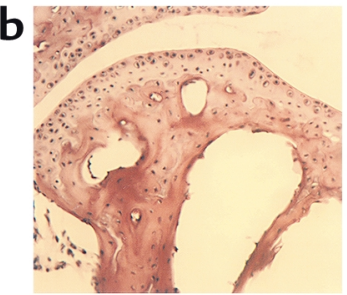

d
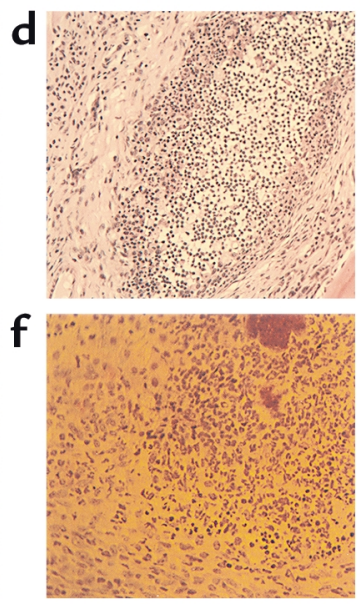

h

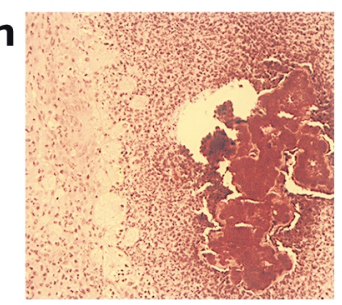


Table 2

Histological examination of joints and abscess formation assessment in heart and kidneys harvested from Map-SA- and Map ${ }^{+}$SA-infected mice

\begin{tabular}{|c|c|c|c|c|}
\hline Infecting strains & Mean arthritis score & Arthritis frequency $(\%)$ & Mean osteomyelitis score & Osteomyelitis frequency (\% \\
\hline $\mathrm{Map}^{+\mathrm{A}}$ & $1.93 \pm 0.38^{\mathrm{B}}$ & $13 / 14(93 \%)^{C}$ & $2.86 \pm 0.40^{\mathrm{D}}$ & $12 / 14(86 \%)^{\mathrm{E}}$ \\
\hline Map $^{-A}$ & $0.93 \pm 0.28$ & $8 / 16(50 \%)$ & $0.06 \pm 0.06$ & $1 / 16(6 \%)$ \\
\hline \multicolumn{5}{|c|}{ Abscess formation (tissue examined) } \\
\hline Infecting strains & Heart & Kidneys & & \\
\hline $\mathrm{Map}^{+\mathrm{A}}$ & $8 / 14(57 \%)^{F}$ & $21 / 28(75 \%)^{\mathrm{F}}$ & & \\
\hline Map $^{-A}$ & $0 / 16(0 \%)$ & $1 / 32(3 \%)$ & & \\
\hline
\end{tabular}

${ }^{A} B A L B / C$ mice were infected intravenously with either $10^{7}$ Map'SA or Map-SA strain Newman. Eight weeks later hind tibiotarsal joints were examined histologically for arthritis and hearts and kidneys were examined grossly and histologically for abscess formation. ${ }^{B} P<0.05$ versus Map ${ }^{-/-} 8$-week group; Student $t$ test. ${ }^{C} P<0.05$ versus Map $P^{-/-} 8$-week group; Fisher's exact test. ${ }^{D} P<0.0001$ versus Map ${ }^{-/-} 8$-week group; Student $t$ test. ${ }^{E} P<0.0001$ versus Map $P^{-/-} 8$-week group; Fisher's exact test. ${ }^{F} P<0.0005$ versus $\mathrm{Map}^{-/-}$8-week group; Fisher's exact test.

of T cells $\left(10^{7}\right.$ nylon wool-enriched T cells/mouse in $500 \mu \mathrm{l}$ of complete $\mathrm{T}$ lymphocyte media [CTL]), mice were challenged in the hind footpads with DbpA, and the DTH response was assessed as described above. CTL medium: RPMI-1640 containing $2 \mathrm{mM}$ L-glutamine, $100 \mathrm{U} / \mathrm{ml}$ penicillin, $100 \mu \mathrm{g} / \mathrm{ml}$ streptomycin, 50 $\mu \mathrm{g} / \mathrm{ml}$ gentamicin, $0.2 \mathrm{mM}$ nonessential amino acids, $11 \mu \mathrm{g} / \mathrm{ml}$ sodium pyruvate, $0.02 \mathrm{M} \mathrm{N}$-2-hydroxyethylpiperaxine- $N^{\prime}$-2ethanesulfonic acid, and $5 \times 10^{-5}$ N 2-mercaptoethanol plus $10 \%$ heat-inactivated FBS. In vitro proliferation of BAT2.2 T cells. The Borrelia burgdorferi-specific mouse Th1 cell line BAT2.2 was stimulated with whole, inactive $B$. burgdorferi (iBb) and syngeneic $(\mathrm{C} 3 \mathrm{H} / \mathrm{Hen})$ antigen-presenting cells (APCs), as described previously $(43,50)$. Briefly, $10^{5}$ BAT2. $2 \mathrm{~T}$ cells were cultured in 96-well flat-bottom plates (Corning-Costar Corp., Cambridge, Massachusetts, USA) along with $3 \times 10^{5}$ mitomycin-treated APCs in CTL medium and Borrelia $(2 \mu \mathrm{g})$ in the presence of various proteins. Each treatment group was done in triplicate in a final volume of $200 \mu \mathrm{l}$ complete medium. Each protein $(10,50$, and $100 \mu \mathrm{g})$ was added to each well, and the $\mathrm{T}$ cells were allowed to proliferate for 24-48 hours at $37^{\circ} \mathrm{C}$. Four hours before the end of the proliferation period, $20 \mu \mathrm{l} /$ well of 3-\{4,5-Dimethylthizol-2-y\}2,5diphenyl-tetraxolium bromide (MTT) $(5 \mathrm{mg} / \mathrm{ml}$; Sigma-Aldrich) was added to each well. After 4 hours of incubation at $37^{\circ} \mathrm{C}, 100 \mu \mathrm{l}$ of solubilization buffer $(0.04$ $\mathrm{N} \mathrm{HCL}$ in isopropanol) was added to each well and absorbance measured at $590 \mathrm{~nm}$. Data are expressed as mean plus or minus SE of the mean of triplicate wells.

Assessment of Map-induced apoptosis of BAT2.2 cells. BAT2.2 T cells (106/well; 5 U IL-2/ml) were incubated in the presence of Map19 or Ace19 in a final volume of $1.5 \mathrm{ml}$ complete media and examined for apoptosis using an Apoptotic DNA Ladder Kit (Roche Molecular Biochemicals, Indianapolis, Indiana, USA), according to the manufacturer's instructions. Two hundred micrograms of each protein was used and apoptosis measured after a 24-hour incubation at $37^{\circ} \mathrm{C}$. Extracted DNA was treated with 10 $\mu \mathrm{g} / \mathrm{ml}$ RNase (DNase free) for 1 hour at room temperature before examination by agarose gel electrophoresis.

Flow cytometry. T cells isolated for adoptive transfer experiments were nylon wool-enriched as described previously and examined by flow cytometric analysis to verify purity (50). Cells were washed in PBS containing 3\% FBS (FACS buffer) and stained with the following mAb's: FITC-conjugated anti-mouse CD8a (Ly2) and

Table 3

Histological examination of joints and abscess formation assessment in heart and kidneys harvested from Map-SA- and Map ${ }^{+}$SA-infected mice reinfected with Map'SA

\begin{tabular}{lccc}
\hline Infecting strains & Mean arthritis score & Arthritis frequency (\%) & Mean osteomyelitis score \\
Map $^{-} /$Map $^{+A, B}$ & $0.84 \pm 0.18^{\mathrm{C}}$ & $14 / 26(54 \%)^{\mathrm{D}}$ & $0.57 \pm 0.23^{\mathrm{C}}$ \\
$\mathrm{Map}^{+} / \mathrm{Map}^{+\mathrm{A}, \mathrm{B}}$ & $1.65 \pm 0.27$ & $18 / 21(86 \%)$ & $1.95 \pm 0.37$ \\
- Map $^{+A, B}$ & $2.06 \pm 0.26$ & $28 / 32(88 \%)$ & $1.48 \pm 0.31$
\end{tabular}

Abscess formation (tissue examined)

$\begin{array}{lcc}\text { Infecting strains } & \text { Heart } & \text { Kidneys } \\ \text { Map }^{-} / \text {Map }^{+A, B} & 12 / 26(46 \%)^{\mathrm{F}, \mathrm{G}} & 13 / 52(25 \%)^{\mathrm{H}} \\ \mathrm{Map}^{+} / \mathrm{Map}^{+\mathrm{A}, \mathrm{B}} & 17 / 19(89 \%) & 33 / 38(86 \%) \\ - \text { Map }^{+\mathrm{A}, \mathrm{B}} & 29 / 31(94 \%) & 48 / 62(77 \%)\end{array}$

ABALB/c mice were infected intravenously with either $10^{7} \mathrm{Map}^{+}$or Map-SA strain Newman or left untreated. Four weeks after primary infection, mice from all groups received $10^{7} \mathrm{Map}^{+} \mathrm{SA}$ intravenously. Four weeks later, the right hind-limb joint was harvested and examined histologically for arthritis and osteomyelitis. In addition, hearts and kidneys were examined grossly and histologically for abscess formation. BThe data are pooled observations from three separate experiments. ${ }^{C} P<0.005$ versus $\mathrm{Map}^{+} / \mathrm{Map}^{+}$group; Students $t$ test. ${ }^{D} P<0.0001$ versus $-/ \mathrm{Map}^{+}$; Fisher's exact test. ${ }^{E} P<0.0001$ versus $\mathrm{Map}^{+} / \mathrm{Map}^{+}$and $-\mathrm{Map}^{+}$groups; Fisher's exact test. F $P<0.005$ versus Map ${ }^{+} /$Map $^{+}$group; Fisher's exact test. ${ }^{G} P<0.0001$ versus $-/$ Map $^{+}$; Fisher's exact test versus $-/$Map $^{+}$; Fisher's exact test. ${ }_{\mathrm{H} P}<0.0001$ versus $\mathrm{Map}^{+} / \mathrm{Map}^{+}$and $-\mathrm{Map}^{+}$groups; Fisher's exact test. 
Table 4

Histological examination of joints harvested from Map-SA- or Map ${ }^{+}$SA-infected nude mice ${ }^{A}$

\begin{tabular}{lcccc}
\hline Infecting strains & Mean arthritis score & Arthritis frequency(\%) & Mean osteomyelitis score & Osteomyelitis frequency (\%) \\
nu/+/Map'SA & $3.00 \pm 0.24^{\mathrm{B}}$ & $16 / 16(100 \%)$ & $3.19 \pm 0.36^{\mathrm{D}, \mathrm{E}}$ & $14 / 16(88 \%)$ \\
nu/+/Map-SA & $1.78 \pm 0.21$ & $21 / 23(91 \%)$ & $0.34 \pm 0.15$ & $5 / 23(22 \%)^{\mathrm{G}}$ \\
nu/nu/Map${ }^{+} \mathrm{SA}$ & $2.58 \pm 0.25$ & $12 / 12(100 \%)$ & $3.00 \pm 0.32$ & $12 / 12(100 \%)$ \\
$n u / n u /$ Map-SA & $2.50 \pm 0.26^{\mathrm{C}}$ & $21 / 24(88 \%)$ & $1.58 \pm 0.20^{\mathrm{F}}$ & $15 / 24(63 \%)$
\end{tabular}

${ }^{A} \mathrm{Hsd} n u / n u$ and $n u /+$ mice were infected intravenously with either $10^{7}$ Map-SA or Map ${ }^{+}$SA strain Newman or left untreated. Four weeks after primary infection, mice from all groups received $10^{7} \mathrm{Map}^{+} \mathrm{SA}$ intravenously. Four weeks later, the right hind-limb joint was harvested and examined histologically for arthritis and osteomyelitis. The data are pooled observations from two separate experiments. ${ }^{\text {B }} P<0.005$ versus $n u /+/$ Map $-\mathrm{SA}$; Student $t$ test. ${ }^{C} P<0.05$ versus $n u /+$ Map $-\mathrm{SA}$ group; Student $t$ test. ${ }^{D} P<0.0001$ versus $n u /+$ Map-SA group; Student $t$ test. ${ }^{E} P<0.001$ versus $n u / n u$ Map-SA group; Student $t$ test. ${ }^{F} P<0.001$ versus $n u /+$ Map-SA group; Student $t$ test. ${ }^{\complement} P<0.05$ versus all groups; Fisher's exact test.

phycoerythrin-conjugated anti-mouse CD4 (L3T4) (PharMingen, San Diego, California, USA). The cells were incubated with the directly conjugated Ab's for 1 hour at $4^{\circ} \mathrm{C}$ and then washed with cold FACS buffer prior to FACS analysis. Annexin V-FITC (PharMingen) and propidium iodide (PI) (Sigma-Aldrich) staining of $10^{6}$ BAT2. 2 cells (5 U IL-2/ml) was performed 24 hours after incubation with either Map19 or $\operatorname{DbpA}(0.2 \mu \mathrm{g} / \mu \mathrm{l})$ or left untreated in CTL media ( $2 \mathrm{ml})$, according to manufacturer's instructions. Cells from all groups were washed in cold FACS buffer and then analyzed on a Coulter EpicProfile flow cytometer (Coulter Corp., Miami, Florida, USA).

\section{Results}

Experimental SA infection. Mice challenged with a sublethal dose of virulent SA can develop severe arthritis and osteomyelitis in addition to abscesses in the heart and kidneys (32). To explore the role that Map might play in the pathogenesis of SA infections, $\mathrm{BALB} / \mathrm{c}$ mice were infected with either $10^{7} \mathrm{Map}^{-} \mathrm{SA}$ or Map ${ }^{+} \mathrm{SA}$ strain Newman. During the initial stages of the infection, the groups of animals inoculated with the two strains were similarly affected, as indicated by recorded weight losses (Figure 1). The mean weight loss recorded for Map-SA- and Map ${ }^{+} S A$-infected mice 7 days after infection was $-2.27 \pm 0.52$ and $-2.58 \pm 0.32$ g, respectively; however, by day 21 after infection, the weight of Map-SA-infected mice returned to postinfection levels compared with $\mathrm{Map}^{+} \mathrm{SA}$-infected mice, which were an average of $1.41 \pm 0.37 \mathrm{~g}$ below preinfection weight readings (Figure 1). Furthermore, bacterial densities between infection groups were indistinguishable during the early stages of infection (Figure 2), suggesting that there were no differences in the capacity of Map-SA to colonize tissues when compared with Map ${ }^{+} S A$ colonization.

Eight weeks after infection, 12 of 14 (86\%) Map ${ }^{+}$SA-infected mice developed osteomyelitis, but only 1 of 16 (6\%) Map-SA-infected mice was diagnosed with a bone infection (Figure 3, a and b, and Table 2). Arthritis frequency and severity were also significantly greater in Map ${ }^{+}$SA-infected mice compared with Map-SAinfected counterparts (Table 2). Furthermore, 8 of 14 (57\%) Map'SA-infected mice developed heart abscesses and 21 of $28(75 \%)$ kidneys examined were similarly affected (Figure 3, fand h, and Table 2). Conversely, none of the $16 \mathrm{Map}^{-S A}$-infected mice developed heart abscesses and only 1 of 32 (3\%) kidneys presented with an abscess (Figure 3 , e and g, and Table 2). Taken together, these results demonstrated that the Map-SA strain was significantly less virulent in our animal model when compared with the parental Map ${ }^{+} S A$ strain, suggesting that Map may be a virulence factor in chronic SA infections. Based on the sequence similarities with MHC class II molecules, we speculated that Map might act as an immunomodulator and that the observed differences between the Map'SA and Map-SA strains were due to suppressed host defenses in Map ${ }^{+} \mathrm{SA}$-infected mice.

This hypothesis was tested in several experiments. First, mice were infected with either $10^{7} \mathrm{Map}^{+} \mathrm{SA}$, Map-SA, or left untreated. Four weeks later, mice from all groups were reinfected with $10^{7} \mathrm{Map}^{+} \mathrm{SA}$ organisms. After an additional 4 weeks, mice from all groups were sacrificed and examined as described above. The results from these experiments suggested that mice initially infected with Map-SA were partially protected against the subsequent $\mathrm{Map}^{+} \mathrm{SA}$ challenge infection. These mice presented with

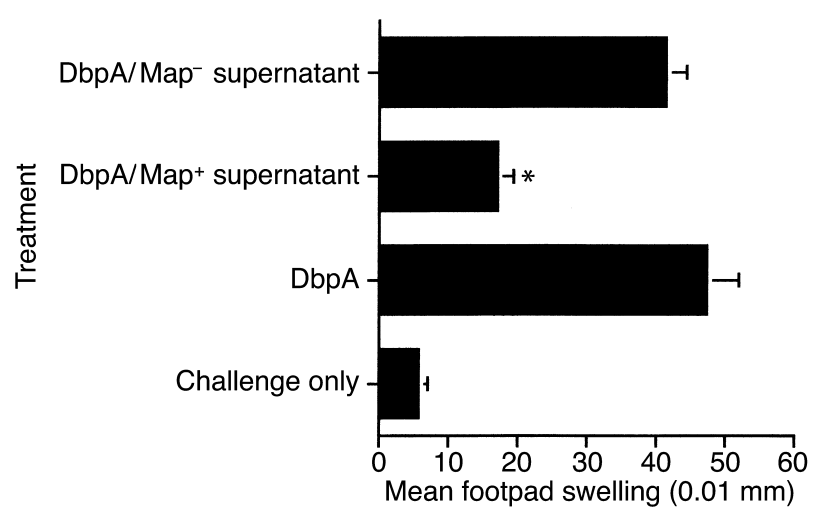

\section{Figure 4}

Native Map-mediated inhibition of DTH. DbpA-immunized mice were treated with native Map on the day of immunization (day 0 ) and on days 2, 4, and 6 after immunization. On day 7, mice were challenged with $\mathrm{DbpA}$, and footpads were measured 0 and 24 hours after challenge. Mice treated with supernatant from Map ${ }^{+} \mathrm{SA}$ had a significantly reduced DTH response compared with immunized and challenged mice ( ${ }^{*} P<0.0001$; Student $t$ test). Data are expressed as the mean \pm SE of five mice. 


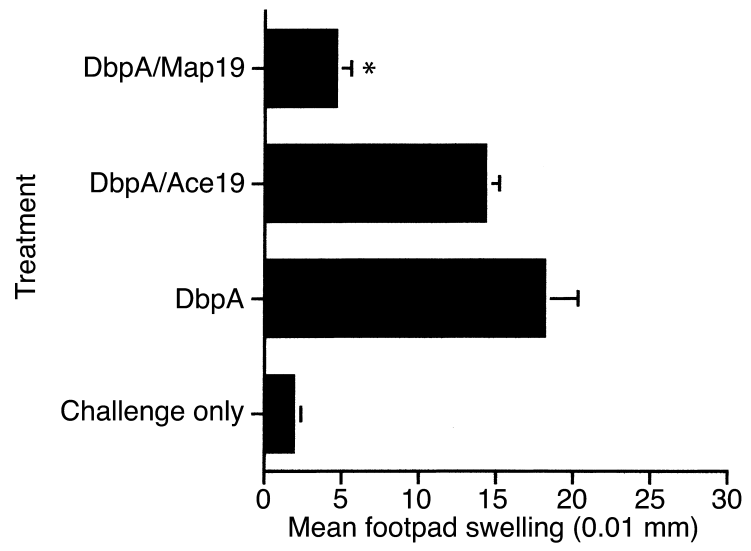

Figure 5

Recombinant Map19-mediated inhibition of DTH. DbpA-immunized mice were treated with recombinant Map19 on the day of immunization (day 0 ) and on days 2, 4, and 6 after immunization. On day 7 , mice were challenged with DbpA and footpads were measured 0 and 24 hours after challenge. Mice treated with recombinant Map19 had a significantly reduced DTH response compared with immunized and challenged mice ( ${ }^{*} P<0.0001$; Student $t$ test). Data are expressed as the mean \pm SE of five mice.

significantly fewer heart (46\%) and kidney (25\%) abscesses following $\mathrm{Map}^{+} \mathrm{SA}$ challenge compared with more than $75 \%$ abscess formation in hearts and kidneys from Map ${ }^{+} S A-i n f e c t e d$ and challenged mice or mice infected with a single dose of $\mathrm{Map}^{+} \mathrm{SA}$ (i.e., -/Map+) (Table 3). Arthritis and osteomyelitis incidence and severity were also significantly reduced in Map-SA-infected mice challenged with $\mathrm{Map}^{+} \mathrm{SA}$ compared with control mice (Table 3). One possible explanation for these data is that Map-SA-infected mice were capable of clearing the infection since their cellular responses were not impaired by Map while concomitantly establishing a memory response capable of clearing the second infection of $\mathrm{MaP}^{+}$SA. If Map functioned to impair T cell-mediated immunity, then mice initially infected with $\mathrm{Map}^{+} \mathrm{SA}$ never fully cleared the infection and were likely not to have been able to develop a memory response capable of recognizing a second SA infection.

SA-infected nude mice. T cell-deficient nude ( $n u / n u)$ and genotype control $(n u /+)$ mice were used to further assess the connection between SA virulence, Map, and $\mathrm{T}$ cell immunity. If Map is an immunomodulator with $\mathrm{T}$ cell inhibitory activities that facilitate SA survival and persistence, then Map-SA-infected $n u / n u$ mice should present with similar disease as $\mathrm{Map}^{+} \mathrm{SA}-$ infected $n u /+$ mice. Map-SA-infected $n u / n u$ mice had significantly higher arthritis and osteomyelitis scores compared with $n u /+\mathrm{Map}^{-S A}$-infected mice. Furthermore, the arthritis scores between $n u / n u / \mathrm{Map}^{-S A}$ - and nu/+/Map ${ }^{+}$SA-infected mice were similar (Figure 3, c and $\mathrm{d}$, and Table 4), even though $n u /+/ \mathrm{Map}^{+} \mathrm{SA}$-infected mice presented with significantly higher osteomyelitis scores (Table 4). Abscess formation was observed in all Map ${ }^{+} \mathrm{SA}$-infected mice but not in mice infected with Map-SA, regardless of genotype. These data suggested that (a) the presence of Map on SA can affect the severity of arthritis and osteomyelitis through a T cell-mediated mechanism, and (b) Map plays a role in abscess formation through a $\mathrm{T}$ cell-independent mechanism(s).

Map-mediated inbibition of DTH. A direct in vivo assay for cellular immunity was used to assess the ability of Map to interfere with DTH. DTH responses are initiated and mediated by Th1 $\mathrm{CD}^{+} \mathrm{T}$ cells in response to recall antigens, and these responses result in specific, measurable inflammation at the site of challenge. Mice immunized with a recombinant form of the $B$. burgdorferi MSCRAMM, DbpA, emulsified in CFA developed a significant DTH response to DbpA as measured by footpad swelling 7 days after immunization (Figure 4 and 5) (41, 44). Mice treated with native Map (Map+SA supernatant), however, on the day of immunization (day 0 ) and days 2, 4, and 6 after immunization had a significantly reduced DTH response to DbpA challenge compared with untreated but immunized control mice and to mice treated with supernatants from Map-SA (Figure 4). Similarly, mice treated with a recombinant form of Map (Map19) had a significantly reduced DTH response following DbpA challenge compared with untreated but immunized controls or the recombinant control protein Ace19-treated mice (Figure 5). Recombinant Map19 inhibited the DTH response in both $\mathrm{BALB} / \mathrm{c}$ and $\mathrm{C} 3 \mathrm{H} / \mathrm{Hen}$ mice following immunization and challenge, demonstrating that Map has inhibitory affects not specific to particular mouse strains (Figure 5 and data not shown, respectively). The effects of Map19 were largely dose dependent with concentrations of $25 \mu \mathrm{g}$ /mouse exhibiting significant inhibitory effects (Figure 6).

Adoptively transferred $T$ cells from Map19-treated mice. Since adoptively transferred immune $\mathrm{T}$ cells confer immunity in syngeneic recipient mice, a cell transfer model was used to further dissect the cellular events underlying Map-mediated inhibition of DTH. Mice

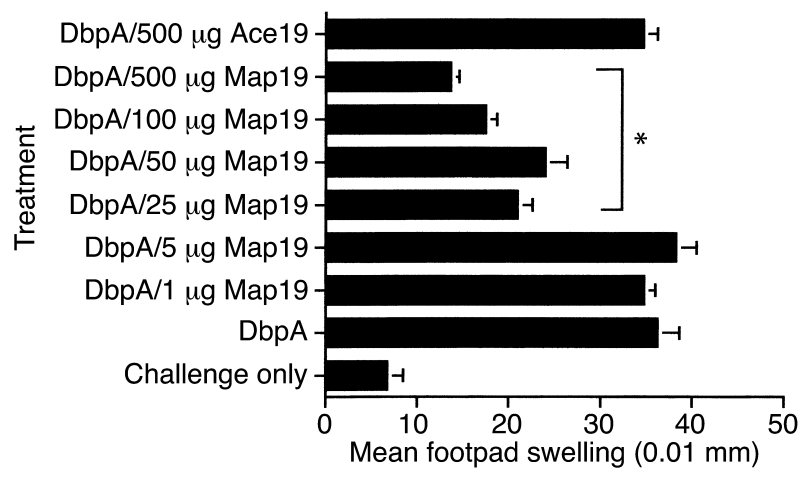

Figure 6

Dose-dependent inhibition of DTH. DbpA-immunized mice were treated with various doses of Map19 (1-500 $\mu \mathrm{g})$ or Ace19 (500 $\mu \mathrm{g})$, as described previously. On day 7, mice were challenged with DbpA, and the footpads measured 0 and 24 hours after challenge. Significant values are indicated by an asterisk $(P<0.05$; Student $t$ test). Data are expressed as the mean \pm SE of five mice. 


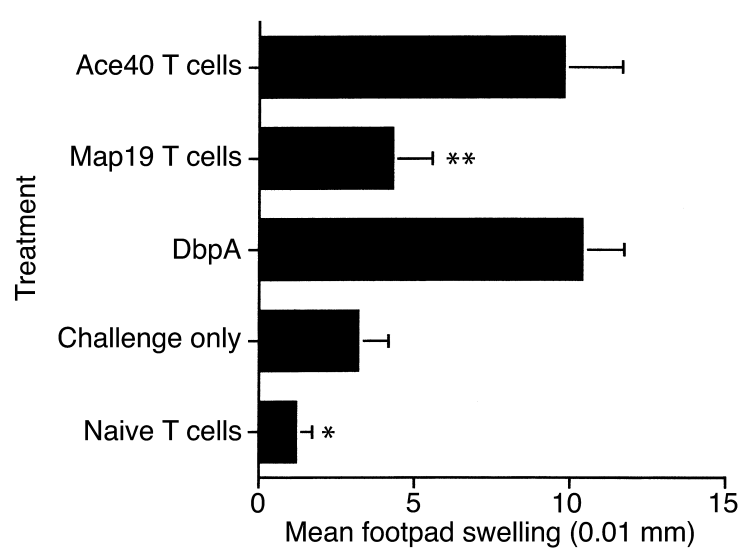

Figure 7

DTH following adoptive T cell transfer. DbpA-immunized mice were treated with either Map19 or Ace40, as described above. On day 7, mice were sacrificed and spleens were harvested and enriched for $T$ cells by nylon wool purification. Cells $\left(5 \times 10^{7}\right)$ were injected intraperitoneally into syngeneic recipients. Twenty-four hours later, recipient mice were challenged with $\mathrm{DbpA}$, and the $\mathrm{DTH}$ response was assessed as described above. T cells from DbpA-immunized Ace40-treated or T cells from DbpA-immunized (untreated) mice elicited a significant DTH response compared with unimmunized but challenged mice or to naive T cell-recipient mice $\left({ }^{*} P<0.04\right.$; Student $t$ test). T cells from DbpA-immunized, Map19-treated mice did not elicit a significant DTH response compared with positive control treatment groups ( ${ }^{*} P<0.001$; Student $t$ test). Data are expressed as the mean $\pm \mathrm{SE}$ of five mice.

immunized with DbpA were either left untreated or injected intraperitoneally with either Map19 or the recombinant control protein Ace 40 on the day of immunization (day 0 ) and on days 2,4 , and 6 after immunization. On day 7 , mice were sacrificed, and single cell suspensions from whole spleens were prepared and enriched for $T$ cells by passage over nylon wool columns (50). Adoptive transfer of nylon wool-purified T cells from Map19-treated mice did not elicit a DTH response to DbpA in naive recipients compared with mice adoptively transferred with enriched $\mathrm{T}$ cells from Ace40-treated mice or untreated immune $\mathrm{T}$ cell control groups (Figure 7). Flow cytometric analysis of nylon wool-collected cells revealed a profile that was $46.83 \% \pm 0.92 \% \mathrm{CD}^{+}$, $31.63 \% \pm 0.96 \% \mathrm{CD}^{+}, 1.2 \% \pm 0.26 \% \mathrm{CD}^{+}{ }^{+} \mathrm{CD}^{+}$, and $20.4 \% \pm 1.33 \% \mathrm{CD}^{-}{ }^{-} \mathrm{CD} 8$. These data are expressed as the mean percentage of positive cells plus or minus SE for the three groups examined.

Inbibition of $T$ cell proliferation and apoptosis assessment. Recombinant Map19 and Ace19 were tested for their ability to inhibit the proliferation of the Borrelia-specific $\mathrm{T}$ cell line BAT $2.2(43,50)$. T cell proliferation was measured 48 hours after plating in the presence of mitomycin $\mathrm{C}$-treated syngeneic APCs and $\mathrm{iBb}$ (50). Proliferation was measured as a function of tetrazolium blue production following a 4-hour incubation in the presence of MTT. Map19-treated BAT 2.2 cells were inhibited significantly from proliferating (Figure 8). Map19 did not inhibit BAT2.2 proliferation if the APCs were preincubated in the presence of either Map19 or Ace19 for 6 hours and then washed prior to the addition of $\mathrm{iBb}$ and BAT2.2 cells, suggesting Map had its inhibitory effects on T cells (data not shown). Furthermore, APCs preincubated with Map19 and iBb for 6 hours induced BAT2.2 proliferation, suggesting that Map did not affect the ability of the APCs to process antigen (data not shown).

Microscopic analysis of BAT2.2 cells cultured in the presence of Map19 revealed significant morphological changes (e.g., cell shrinkage) compared with untreated cells or cells cultured in the presence of control proteins (data not shown), suggesting that apoptosis or necrosis but not anergy were likely induced by Map. FACS analysis of BAT2.2 cells stained with annexin V-FITC and PI revealed that $76 \%$ of BAT2.2 Map19-treated cells (Figure 9c) were both annexin V-FITC/PI positive compared with almost $11 \%$ double-positive cells for both untreated and DbpA-treated cells (Figure 9, a and b, respectively). FACS analysis at earlier time points did not reveal significant differences between treatment groups (data not shown). Since cells that have already undergone an apoptotic death will eventually also stain positive for PI, it was not possible to distinguish if Map-treated cells in this assay were in a state of late apoptosis or necrosis (51). To differentiate between these forms of cell death, DNA extracted from BAT2.2 T cells incubated in the presence of Map19 was examined for fragmentation by gel electrophoresis (Figure 10). DNA extracted from Map19treated cells (lane 3 ) was fragmented comparable to the apoptotic-positive control DNA (lane 5) but not DNA extracted from untreated (lane 2) or Ace40-treated (lane 4) T cells (Figure 10), suggesting that Map can, at least in vitro, prevent $\mathrm{T}$ cell function by induction of apoptosis.

\section{Discussion}

Mechanisms of immune escape are used by many infectious agents affecting humans. The nature of these strategies significantly vary and can be classified into various categories: the generation of physical barriers (biofilm

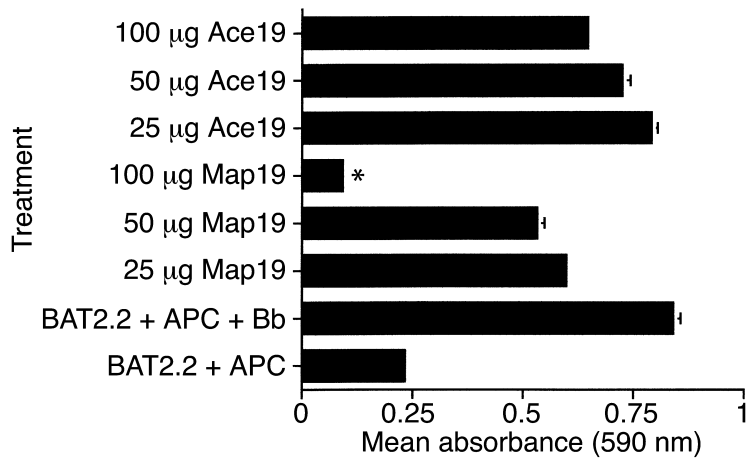

Figure 8

Map-induced inhibition of T cell proliferation. BAT2.2 T cell proliferation was measured after 48 hours in culture in the presence of APCs, and antigen in the presence of Map 19 or Acel9 at various concentrations. ${ }^{*} P<0.0001$ compared with all other treatment groups; Student $t$ test. Data are expressed as the mean absorbance \pm SE of triplicate wells. 

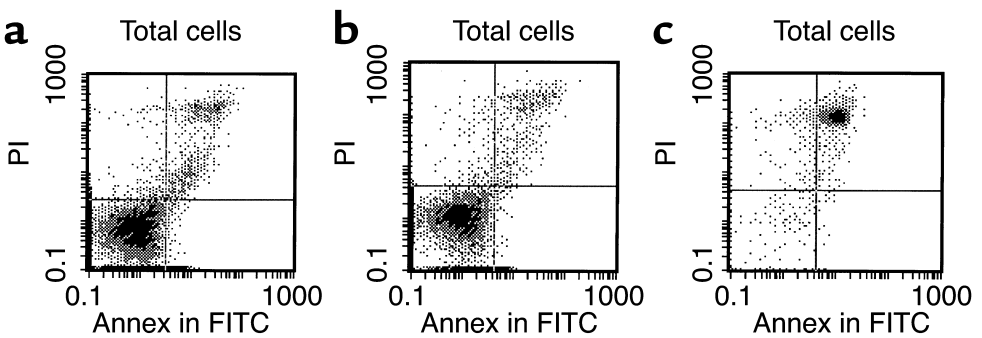

\section{Figure 9}

The effect of Map19 on annexin V/PI staining. BAT2. 2 cells $\left(10^{6}\right)(5 \cup \mathrm{IL}-2 / \mathrm{ml})$ were incubated in media alone (a) or in the presence of either $400 \mu \mathrm{g}$ of either Ace40 (b) or Map19 (c) for 24 hours and analyzed by FACS following incubations with annexin V-FITC and PI. formation) that protect bacteria against immune attack $(52,53)$; the secretion of immunoregulatory cytokine analogs or the induction of host cytokines that potentiate nonprotective immunity, resulting in pathogen survival (54-58); antigenic variation, which can prevent the generation of a protective immune response (59-61); antigenic mimicry, which can result in either immune modulation (e.g., MHC I analogs) or sequestration of the pathogen from the immune system $(62,63)$; toxin and protease production, which can destroy different cell types, including immune cells $(2,52)$; and finally, direct modulation of host cell functions, which can result in the induction or inhibition of apoptosis, respectively, depending on the pathogen (64-69).

Reinfection of humans with SA is one of the hallmarks of diseases caused by this pathogen, and a difficulty in clearing these types of infections is not only a function of disseminated disease but of SA immune escape mechanisms (23-26). One possible reason for recurring infections is that leukocytes from patients with chronic or recurrent SA infections have impaired chemotactic, phagocytic, and bactericidal functions $(25,30,31)$. Whether these defects in lymphocyte function were a result of the bacterial infection or a preexisting condition in these individuals is not known $(25,30,31)$. More specifically, superantigens and protein A produced by SA during an infection serve immune-evasion functions that may potentiate ongoing and recurrent infections (2).

Here we describe a third SA MIM (microbial immunomodulatory molecule) with potential $\mathrm{T}$ celllimiting properties. The first observation suggesting Map acted in this capacity stemmed from double infection studies in which a primary infection with Map-SA conferred significant protection against reinfection with $\mathrm{Map}^{+} \mathrm{SA}$. This contrasted significantly with the pathologies observed in mice receiving primary and secondary $\mathrm{Map}^{+} \mathrm{SA}$ infections. One explanation for these data is that $\mathrm{T}$ cell-mediated responses in $\mathrm{Map}^{+} \mathrm{SA}$-infected mice were abrogated by the presence of Map. In contrast, Map-SA-infected mice developed cell-mediated immunity over the course of infection, resulting in bacterial clearance and in a memory response capable of controlling a secondary $\mathrm{Map}^{+} \mathrm{SA}$ infection. That a primary Map-SA infection conferred significant but incomplete protection against $\mathrm{Map}^{+} \mathrm{SA}$ challenge suggested that the balance or competition between an anamnestic response and Map-mediated immunomodulation could be affected by the challenge dose. Although these data suggested that Map acted as an immunoregulatory molecule, we could not exclude the following two possibilities: first, if Map is a critical adhesin required during the infection process, its removal may have resulted in an attenuated SA strain that served to "vaccinate" mice against the second Map ${ }^{+} \mathrm{SA}$ infection. This is not a likely scenario since Map-deficient SA still efficiently adhere to individual ECM molecules $(19,20)$. Furthermore, the mean weight loss between Map-SA- and Map ${ }^{+}$SA-infected mice was similar during the first weeks after infection, and the bacterial densities in various tissues were indistinguishable between infection groups, suggesting that bacterial adhesion, a critical early step during infection, was not compromised in Map-SA. This weight-loss pattern is significantly different from that recorded for mice infected with SA deficient in the collagen-binding protein CNA (CNA-SA). Weight loss differences in these animals, compared with $\mathrm{CNA}^{+} \mathrm{SA}$-infected controls diverged from the start of the infection process (E.L. Brown et al., unpublished observations). Second, a diminished disease state following Map-SA infection may have been a result of polar effects caused by map inactivation following transformation resulting in the inactivation of other genes required for SA survival or virulence. Although a mapcomplemented Map-SA strain Newman is not yet available, the significant effects of both isolated native Map

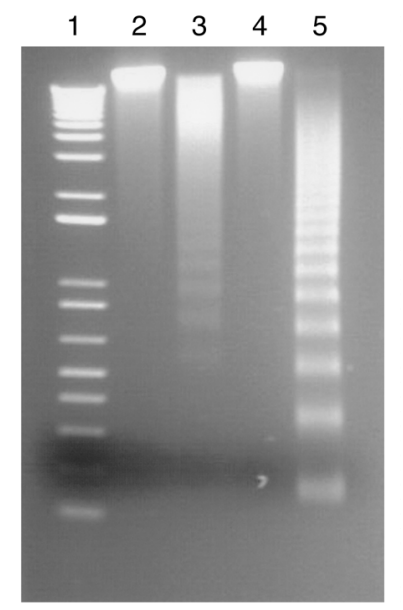

Figure 10

Map-induced apoptosis of BAT2.2 T cells. BAT2.2 cells $\left(2 \times 10^{6}\right)(5$ $\mathrm{U} \mathrm{IL}-2 / \mathrm{ml}$ ) were incubated in media alone (lane 2) or in the presence of either $100 \mu \mathrm{g}$ Map19 (lane 3) or Ace40 (lane 4). DNA from U937 cells were used as a positive control (lane 5). Lane 1, 100-bp ladder. 
and of recombinant Map19 on cellular immunity strongly suggested that the lack of virulence observed for Map-SA was a function of the bacteria's inability to affect host immunity and not a result of the map inactivation process. In addition, $n u / n u$ mice infected with Map-SA presented with more severe arthritis compared with $n u /+$ mice infected with Map-SA. Interestingly, abscess formation was absent in $n u / n u$ and $n u /+$

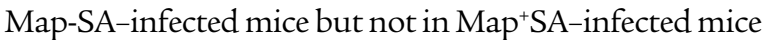
of either genotype. These data suggested a potential role for $\mathrm{T}$ cells in controlling joint pathology but not in protection against abscess formation. These experiments somewhat contradict findings in a rat model that suggested that $T$ cells are critical for abscess formation and with recent work describing Map as an anti-inflammatory agent in a mouse peritonitis model $(20,70)$. However, both of these studies examined acute SA infections in contrast to the assessment of chronic disease described here. Furthermore, the infection routes (intraperitoneal) and the parameters used to assess disease were significantly different in both studies $(20,70)$. These differences make it difficult to reconcile the antiinflammatory effects of Map described in a thioglycollate-induced peritonitis model with the abscesses and severe joint disease caused by a chronic SA infection (20).

Additional evidence suggesting that Map affected $\mathrm{T}$ cell function stemmed from experiments demonstrating that Map inhibited DTH responses and induced T cell death in vitro most likely by apoptosis. The effects of Map on $\mathrm{T}$ cell function appeared only to affect mature T cells stimulated in the context of antigen and MHC II. It is interesting to speculate that this effect of Map on T cells is a function of the homology between Map and MHC class II molecules since the proliferation of naive $\mathrm{T}$ cells following incubation with concanavalin A or by Ab crosslinking of the $T$ cell receptor was not inhibited by Map19 (McIntyre and Miyamoto, unpublished observations). Interference of Map with the interactions between activated T cells and MHC class II-bearing APCs may explain why Map only affected $\mathrm{T}$ cell proliferation in the context of antigen and APCs. Furthermore, a human T cell line cultured in the presence of plate-bound fibronectin and $\alpha \mathrm{CD} 3$ proliferated in the presence of Map19 (B.W. McIntyre and Y.J. Miyamoto, unpublished observations). These data suggested that activated $T$ cells, but not naive $\mathrm{T}$ cells, were susceptible to inhibition of proliferation by Map and that $\mathrm{T}$ cell lines induced to proliferate via "nonclassical" pathways bypassed Map-mediated mechanisms that resulted in the loss of $\mathrm{T}$ cell function.

Sequence analysis of the SA genome revealed four open-reading frames (ORFs) encoding Map-like proteins in meticillin-resistant SA strain N315 (38). The ORF designated SA1751 encodes a protein with a 69\% identity to Map from strain FDA574 $(21,38)$. The SA1751 sequence is truncated by a stop codon immediately after an adenine-rich region, and expansion of this region by one adenine would remove the stop codon; the adjacent MHC II homologous region (SA1750) would be encoded (38). This suggested that SA can express longer or shorter forms of Map by modulating the length of the alanine repeat region (38). The remaining ORFs (SA2006 and SA0841) encode proteins with 34 and $44 \%$ identity, respectively, to the FDA574 Map protein. The role of these Map homologues in SA infection is unknown at this time. Perhaps the potential to encode a variety of MHC II-like proteins can serve to potentiate survival of various SA strains in mammals of varied genetic backgrounds. Extensive searches for Map homologues using the available public databases revealed no similar proteins in other bacteria.

SA uses various survival strategies that allow it to persist in mammalian hosts. Furthermore, persistent and recurrent SA infections point to mechanisms that obstruct the development of protective immunity. One of the functions of the Map protein suggested that it may function to impede the development and maintenance of memory responses. Apoptotic modulation by MIMs is just one mechanism of immune evasion used by human pathogens. Elucidation of the structure of this class of molecules, their functions, and mechanisms of action may be used to design strategies to prevent or treat disease.

\section{Acknowledgments}

This work was supported by the Department of Health and Human Services, grants from the Center for Disease Control (CCU618387) to E. Brown, by NIH grant AI20624 to M. Höök and grant CA-62596 to B. McIntyre, and Cancer Immunobiology Training Program Grant CA09598 to Y. Miyamoto. We thank Andrew Spicer for critical review of the manuscript and Karen Ramirez for flow cytometry operation and technical assistance.

1. Kissane, J.M. 1997. Staphylococcal infections. In Pathology of Infectious Diseases. Vol. I. D.H. Connor, F.W. Chandler, H.J. Schwartz, H.J. Manz, and E.E. Lack, editors. Appleton and Lange. Stamford, Connecticut, USA. 805-816.

2. Lowy, F.D. 1998. Staphylococcus aureus infections. N. Engl. J. Med. 339:520-532

3. Rupp, M.E. 1997. Infections of intravascular catheters and vascular devices. In The staphylococci in human disease. K.B. Crossley and G.L. Archer, editors. Churchill Liningstone. New York, New York, USA. 379-399.

4. Tacconelli, E., Tumbarello, M., and Cauda, R. 1998. Staphylococcus aureus infections. N. Engl. J. Med. 339:2026-2027.

5. Petros, S., et al. 1998. Severe community acquired pneumonia due to Staphylococcus aureus. Intensive Care Med. 24:189.

6. Kim, H.S., Weilbaecher, D.G., Lie, J.T., and Titus, J.L. 1978. Myocardial abscesses. Am. J. Clin. Pathol. 70:18-23.

7. Hiramatsu, K., Cui, L., Kuroda, M., and Ito, T 2001. The emergence and evolution of methicillin-resistant Staphylococcus aureus. Trends Microbiol. 9:486-493.

8. Patti, J.M., Allen, B.L., McGavin, M.J., and Höök, M. 1994. MSCRAMMmediated adherence of microorganisms to host tissues. Annu. Rev. Microbiol. 48:585-617.

9. Herrmann, M., Suchard, S.J., Boxer, L.A., Waldvogel, F.A., and Lew, P.D. 1991. Thrombospondin binds to Staphylococcus aureus and promotes staphylococcal adherence to surfaces. Infect. Immun. 59:279-288.

10. Fujigaki, Y., et al. 1998. Glomerular injury induced by cationic $70-k D$ staphylococcal protein; specific immune response is not involved in early phase in rats. J. Pathol. 184:436-445.

11. Chhatwal, G.S., Preissner, K.T., Muller-Berghaus, G., and Blobel, H. 1987. Specific binding of the human S protein (vitronectin) to streptococci, Staphylococcus aureus, and Escherichia coli. Infect. Immun. 55:1878-1883.

12. Jahreis, A., Beckheinrich, P., and Haustein, U.F. 2000. Effects of two novel cationic staphylococcal proteins (NP-tase and p70)and enterotoxin B on $\mathrm{IgE}$ synthesis and interleukin-4 and interferon-gamma production in patients with atopic dermatitis. Br. J. Dermatol. 142:680-687.

13. Jahreis, A., et al. 1995. Two novel cationic staphylococcal proteins induce 
IL-2 secretion, proliferation and immunoglobulin synthesis in peripheral blood mononuclear cells (PBMC) of both healthy controls and patients with common variable immunodeficiency (CVID). Clin. Exp. Immunol. 100:406-411.

14. Hudson, M.C., Ramp, W.K., and Frankenburg, K.P. 1999. Staphylococcus aureus adhesion to bone matrix and bone-associated biomaterials. FEMS Microbiol. Lett. 173:279-284.

15. Lopes, J.D., dos Reis, M., and Brentani, R.R. 1985. Presence of laminin receptors in Staphylococcus aureus. Science. 229:275-277.

16. O'Connell, D.P., et al. 1998. The fibrinogen-binding MSCRAMM (clumping factor) of Staphylococcus aureus has a $\mathrm{Ca}^{2+}$-dependent inhibitory site. J. Biol. Chem. 273:6821-6829.

17. Vercellotti, G.M., et al. 1985. Extracellular matrix proteins (fibronectin, laminin, and type IV collagen) bind and aggregate bacteria. Am. J. Pathol. 120:13-21

18. Wann, E.R., Gurusiddappa, S., and Höök, M. 2000. The fibronectinbinding MSCRAMM FnbpA of Staphylococcus aureus is a bifunctional protein that also binds to fibrinogen. J. Biol. Chem. 275:13863-13871.

19. Kreikemeyer, B., McDevitt, D., and Podbielski, A. 2002. The role of the Map protein in S. aureus matrix protein and eukaryotic cell adherence. Int. J. Med. Microbiol. 292:283-295.

20. Chavakis, T., et al. 2002. Staphylococcus aureus extracellular adherence protein serves as anti- inflammatory factor by inhibiting the recruitment of host leukocytes. Nat. Med. 8:687-693.

21.Jonsson, K., McDevitt, D., McGavin, M.H., Patti, J.M., and Höök, M. 1995. Staphylococcus aureus expresses a major histocompatibility complex class II analog. J. Biol. Chem. 270:21457-21460

22. Guillen, C., et al. 2002. Enhanced Th1 response to Staphylococcus aureus infection in human lactoferrin-transgenic mice. J. Immunol. 168:3950-3957.

23. Chang, H.R., et al. 2000. Use of pulsed-field gel electrophoresis in the analysis of recurrent Staphylococcus aureus infections in patients on continuous ambulatory peritoneal dialysis. Am. J. Nephrol. 20:463-467.

24. Hartstein, A.I., Mulligan, M.E., Morthland, V.H., and Kwok, R.Y. 1992 Recurrent Staphylococcus aureus bacteremia. J. Clin. Microbiol. 30:670-674.

25. Monteil, M., Hobbs, J., and Citron, K. 1987. Selective immunodeficiency affecting staphylococcal response. Lancet. 2:880-883.

26. Shayegani, M., De Courcy, S.J., Jr., and Mudd, S. 1973. Cell-mediated immunity in mice infected with $S$. aureus and elicited with specific bacterial antigens. J. Reticuloendothel. Soc. 14:44-51.

27. Easmon, C.S., and Glynn, A.A. 1975. Cell-mediated immune responses in Staphylococcus aureus infections in mice. Immunology. 29:75-85.

28. Ficker, L., Seal, D., and Wright, P. 1989. Staphylococcal infection and the limbus: study of the cell-mediated immune response. Eye. 3:190-193.

29. Sarai, Y., et al. 1977. Immunological properties in staphylococcal toxic epidermal necrolysis. Dermatologica. 155:315-318.

30. Verbrugh, H.A., et al. 1980. Phagocytic and chemotactic function of polymorphonuclear and mononuclear leucocytes in patients with recurrent staphylococcal infections. Scand. J. Infect. Dis. 12:111-116.

31. Valmin, K., Hallberg, T., and Hedstrom, S.A. 1982. Recurrent Stapbylococcal furunculosis: lymphocyte subsets and plasma immunoglobulins. Scand. J. Infect. Dis. 14:153-154.

32. Bremell, T., Lange, S., Yacoub, A., Ryden, C., and Tarkowski, A. 1991 Experimental Staphylococcus aureus arthritis in mice. Infect. Immun. 59:2615-2623.

33. Sloane, R., et al. 1991. A toxic shock syndrome toxin mutant of Staphy lococcus aureus isolated by allelic replacement lacks virulence in a rabbit uterine model. FEMS Microbiol. Lett. 62:239-244.

34. Hussain, M., et al. 2002. Insertional inactivation of Eap in Staphylococcus aureus strain Newman confers reduced staphylococcal binding to fibroblasts. Infect. Immun. 70:2933-2940.

35. Kreiswirth, B.N., et al. 1983. The toxic shock syndrome exotoxin structural gene is not detectably transmitted by a prophage. Nature. 305:709-712.

36. Duthie, E.S., and Lorenz, L.L. 1952. Staphylococcal coagulase: mode of action and antigenicity. J. Gen. Microbiol. 6:95-107.

37. Ponnuraj, K., et al. 2002. Crystallization and preliminary $\mathrm{x}$-ray crystallographic analysis of Ace: a collagen-binding MSCRAMM from Enterococcus faecalis. Biochim. Biophys. Acta. 1596:173-176.

38. Kuroda, M., et al. 2001. Whole genome sequencing of meticillin-resistant Staphylococcus aureus. Lancet. 357:1225-1240.

39. Visai, L., et al. 2000. Monoclonal antibodies to CNA, a collagen-binding microbial surface component recognizing adhesive matrix molecules, detach Staphylococcus aureus from a collagen substrate. J. Biol. Chem. 275:39837-39845

40. Rich, R.L., et al. 1999. Ace is a collagen-binding MSCRAMM from Enterococcus faecalis. J. Biol. Chem. 274:26939-26945.

41. Guo, B.P., Brown, E.L., Dorward, D.W., Rosenberg, L.C., and Höök, M 1998. Decorin-binding adhesins from Borrelia burgdorferi. Mol. Microbiol. 30:711-723.

42. Maniatis, T., Fritsch, E.F., and Sambrook, J. 1989. Molecular cloning: A laboratory manual. Cold Spring Harbor Laboratory Press. Cold Spring Harbor, New York, USA. A.3

43. Brown, E.L., Ullrich, S.E., Pride, M., and Kripke, M.L. 2001. The effect of UV irradiation on infection of mice with Borrelia burgdorferi. Photochem. Photobiol. 73:537-544.

44. Brown, E.L., et al. 2001. Resistance to Lyme disease in decorin-deficient mice. J. Clin. Invest. 107:845-852.

45. McGavin, M.H., Krajewska-Pietrasik, D., Ryden, C., and Höök, M. 1993. Identification of a Staphylococcus aureus extracellular matrix-binding protein with broad specificity. Infect. Immun. 61:2479-2485.

46. Patti, J.M., et al. 1994. The Staphylococcus aureus collagen adhesin is a virulence determinant in experimental septic arthritis. Infect. Immun. 62:152-161.

47. Switalski, L.M., et al. 1993. A collagen receptor on Staphylococcus aureus strains isolated from patients with septic arthritis mediates adhesion to cartilage. Mol. Microbiol. 7:99-107.

48. Joh, H.J., House-Pompeo, K., Patti, J.M., Gurusiddappa, S., and Höök, M. 1994. Fibronectin receptors from gram-positive bacteria: comparison of active sites. Biochemistry. 33:6086-6092.

49. Brown, E.L., et al. 1995. Modulation of immunity to Borrelia burgdorferi by ultraviolet irradiation: differential effect on Th1 and Th 2 immune responses. Eur. J. Immunol. 25:3017-3022.

50. Pride, M.W., et al. 1998. Specific Th1 cell lines that confer protective immunity against experimental Borrelia burgdorferi infection in mice. J. Leukoc. Biol. 63:542-549.

51. Vermes, I., Haanen, C., Steffens-Nakken, H., and Reutelingsperger, C. 1995. A novel assay for apoptosis. Flow cytometric detection of phosphatidylserine expression on early apoptotic cells using fluorescein labelled Annexin V. J. Immunol. Methods. 184:39-51.

52. Kharazmi, A. 1991. Mechanisms involved in the evasion of the host defence by Pseudomonas aeruginosa. Immunol. Lett. 30:201-205.

53. Martin-Lopez, J.V., et al. 2002. Detection of Staphylococcus aureus clinical isolates harboring the ica gene cluster needed for biofilm establishment. J. Clin. Microbiol. 40:1569-1570.

54. Suzuki, T., et al. 1995. Viral interleukin 10 (IL-10), the human herpes virus 4 cellular IL-10 homologue, induces local anergy to allogeneic and syngeneic tumors. J. Exp. Med. 182:477-486.

55. Engele, M., et al. 2002. Induction of TNF in human alveolar macrophages as a potential evasion mechanism of virulent Mycobacterium tuberculosis. J. Immunol. 168:1328-1337.

56. de Diego, J., Punzon, C., Duarte, M., and Fresno, M. 1997. Alteration of macrophage function by a Trypanosoma cruzi membrane mucin. J. Immunol. 159:4983-4989.

57. Abraham, S.N., Beachy, E.H., and Simpson, W.A. 1983. Adherence of streptococcus pyogenes, Escherichia coli, and Pseudomonas aeruginosa to fibronectin-coated and uncoated epithelial cells. Infect. Immun. 41:1261-1268.

58. Akridge, R.E., Oyafuso, L.K., and Reed, S.G. 1994. IL-10 is induced during HIV-1 infection and is capable of decreasing viral replication in human macrophages. J. Immunol. 153:5782-5789.

59. Donelson, J.E., Hill, K.L., and El-Sayed, N.M. 1998. Multiple mechanisms of immune evasion by African trypanosomes. Mol. Biochem. Parasitol. 91:51-66.

60. Kyes, S., Horrocks, P., and Newbold, C. 2001. Antigenic variation at the infected red cell surface in malaria. Annu. Rev. Microbiol. 55:673-707.

61. Lawrenz, M.B., et al. 1999. Human antibody responses to VlsE antigenic variation protein of Borrelia burgdorferi. J. Clin. Microbiol. 37:3997-4004.

62. Wurzner, R. 1999. Evasion of pathogens by avoiding recognition or eradication by complement, in part via molecular mimicry. Mol. Immunol. 36:249-260.

63. Farrell, H.E., et al. 1997. Inhibition of natural killer cells by a cytomegalovirus MHC class I homologue in vivo. Nature. 386:510-514.

64. Boulton, I.C., and Gray-Owen, S.D. 2002. Neisserial binding to CEACAM1 arrests the activation and proliferation of CD4+ T lymphocytes. Nat. Immunol. 3:229-236.

65. Cuff, S., and Ruby, J. 1996. Evasion of apoptosis by DNA viruses. Immunol. Cell Biol. 74:527-537.

66. Das, G., Vohra, H., Saha, B., Agrewala, J.N., and Mishra, G.C. 1998. Leishmania donovani infection of a susceptible host results in apoptosis of Th1-like cells: rescue of anti-leishmanial CMI by providing Th1-specific bystander costimulation. Microbiol. Immunol. 42:795-801.

67. Monack, D.M., Mecsas, J., Ghori, N., and Falkow, S. 1997. Yersinia signals macrophages to undergo apoptosis and YopJ is necessary for this cell death. Proc. Natl. Acad. Sci. USA. 94:10385-10390.

68. Nunes, M.P., Andrade, R.M., Lopes, M.F., and DosReis, G.A. 1998. Activation-induced $T$ cell death exacerbates Trypanosoma cruzi replication in macrophages cocultured with CD4+ T lymphocytes from infected hosts. Immunol. 160:1313-1319.

69. Wei, S., et al. 2002. Toxoplasma gondii-infected human myeloid dendritic cells induce T-lymphocyte dysfunction and contact-dependent apoptosis. Infect. Immun. 70:1750-1760.

70. Tzianabos, A.O., and Kasper, D.L. 2002. Role of T cells in abscess formation. Curr. Opin. Microbiol. 5:92-96. 